\title{
Islet Inflammation, Hemosiderosis, and Fibrosis in Intrauterine Growth-Restricted and High Fat-Fed Sprague-Dawley Rats
}

Viviane Delghingaro-Augusto, ${ }^{*}$ Leili Madad, ${ }^{*}$ Arin Chandra, ${ }^{\dagger}$ Charmaine J. Simeonovic, ${ }^{\ddagger}$ Jane E. Dahlstrom, ${ }^{* \dagger}$ and Christopher J. Nolan ${ }^{\star}$

From the Australian National University Medical School* and the John Curtin School of Medical Research, ${ }^{\ddagger}$ Australian National University, Acton; and the Departments of Anatomical Pathology ${ }^{\dagger}$ and Endocrinology and Diabetes, ${ }^{\S}$ The Canberra Hospital, Garran, Australia

Accepted for publication

January 28, 2014.

Address correspondence to Christopher J. Nolan, Ph.D., Department of Endocrinology and Diabetes, The Canberra Hospital, PO Box 11, Woden, ACT 2606, Australia. E-mail: christopher.nolan@anu.edu.au.

\begin{abstract}
Prenatal and postnatal factors such as intrauterine growth restriction (IUGR) and high-fat (HF) diet contribute to type 2 diabetes. Our aim was to determine whether IUGR and HF diets interact in type 2 diabetes pathogenesis, with particular attention focused on pancreatic islet morphology including assessment for inflammation. A surgical model of IUGR (bilateral uterine artery ligation) in SpragueDawley rats with sham controls was used. Pups were fed either HF or chow diets after weaning. Serial measures of body weight and glucose tolerance were performed. At 25 weeks of age, rat pancreases were harvested for histologic assessment. The birth weight of IUGR pups was $13 \%$ lower than that of sham pups. HF diet caused excess weight gain, dyslipidemia, hyperinsulinemia, and mild glucose intolerance, however, this was not aggravated further by IUGR. Markedly abnormal islet morphology was evident in 0 of 6 sham-chow, 5 of 8 sham-HF, 4 of 8 IUGR-chow, and 8 of 9 IUGR-HF rats (chisquare, $P=0.007$ ). Abnormal islets were characterized by larger size, irregular shape, inflammation with CD68-positive cells, marked fibrosis, and hemosiderosis. $\beta$-Cell mass was not altered by IUGR. In conclusion, HF and IUGR independently contribute to islet injury characterized by inflammation, hemosiderosis, and fibrosis. This suggests that both HF and IUGR can induce islet injury via converging pathways. The potential pathogenic or permissive role of iron in this process of islet inflammation warrants further investigation. (Am J Pathol 2014, 184: 1446-1457; http://dx.doi.org/ 10.1016/j.ajpath.2014.01.024)
\end{abstract}

Type 2 diabetes is a metabolic disease characterized by hyperglycemia and altered lipid metabolism caused by a failure of pancreatic $\beta$-cells to sustain adequate insulin secretion in response to variable degrees of overweight or obesity and insulin resistance. ${ }^{1-3}$ The worldwide prevalence of diabetes in adults is estimated to increase to $7.7 \%$ by 2030. ${ }^{4}$ The increased rate of type 2 diabetes has been associated with overnutrition and lack of physical exercise. $^{5,6}$

Epidemiologic and experimental studies additionally have provided evidence linking adverse intrauterine environments of both undernutrition and overnutrition with later development of adult diseases, including obesity and type 2 diabetes. $^{6-10}$ In developed countries, placental insufficiency leading to an inadequate supply of nutrients and oxygen to the fetus is the most common cause of fetal intrauterine growth restriction (IUGR). ${ }^{1,12}$ To investigate the implications of IUGR on postnatal development, several rodent models inducing IUGR have been developed. The methods used include total energy restriction, protein restriction, glucocorticoid exposure, and uteroplacental insufficiency induced surgically by bilateral uterine artery ligation (BUAL). ${ }^{13-21}$ Many of these models result in abnormal pancreatic islet development, with evidence of diminished insulin secretory capacity resulting in glucose intolerance and often diabetes. ${ }^{13-15,17,19,20}$

\footnotetext{
Supported by a project grant from the National Health and Medical Research Council 418071 (C.J.N.).

Disclosures: None declared.
} 
The BUAL model in Sprague-Dawley (SD) rats was described by Simmons et al. ${ }^{17}$ IUGR is induced by ligation of both uterine arteries at day 18 of a 22-day rat pregnancy. In their laboratory, IUGR rat pups have a short period of catch-up growth, by 10 weeks of age the rats become overweight and hypertriglyceridemic, and by 15 weeks of age they develop frank diabetes. The diabetes is associated with loss of $\beta$-cell mass, evident by 15 weeks of age. In addition, IUGR significantly alters DNA methylation and gene expression in pancreatic islets, leading to a progressive silencing of the pancreatic and duodenal homeobox 1 gene $(P d x l) .^{22,23}$ PDX-1 is a key transcription factor that is necessary for pancreas development and islet $\beta$-cell differentiation. Of interest, treatment of neonatal IUGR rats with the glucagon-like peptide 1 analog exendin- 4 prevents diabetes development and partially recovers islet Pdx $1 \mathrm{mRNA}$ expression, vascular endothelial growth factor expression, vascularity, and $\beta$-cell mass, ${ }^{24,25}$ such that the IUGR effects on islet development potentially are reversible if treated early. In contrast, it is likely that other postnatal environmental factors, such as a high-fat (HF) diet, will worsen the detrimental effects of IUGR on islet development.

There is increasing interest in the role of inflammation in the pathogenesis of type 2 diabetes, including islet injury. ${ }^{26,27}$ It is unknown if IUGR can induce islet inflammation, but inflammatory markers have been found to be increased in cord blood in small-for-gestational-age human neonates, ${ }^{28}$ and inflammation has been shown in the amniotic fluid and blood of the BUAL rat model of IUGR. ${ }^{29}$

By using the BUAL model of placental insufficiency in SD rats, our aim was to investigate the interaction between IUGR and HF diet after weaning on the development of diabetes, with particular focus on pancreatic islet morphology. Our data suggest that IUGR and HF diet independently can cause islet injury, as shown by islet inflammation, hemosiderosis, and fibrosis. The SD IUGR rats in this study, however, did not develop diabetes because they were able to compensate for the islet injury with preservation of islet $\beta$-cell mass.

\section{Materials and Methods}

\section{Animals}

Female pregnant SD rats, mated at 10 weeks of age, were purchased from the Animal Resources Centre (Perth, Western Australia, Australia). Rats were housed at The Canberra Hospital animal facility in individual cages, in a temperature- and humidity-controlled environment on a 12-hour light/dark cycle, with free access to rodent chow (Gordon's Specialty Stock Feeds, Yanderra, New South Wales, Australia) and tap water. SD pregnant rats were assigned randomly to three experimental groups: i) bilateral uterine artery ligated (BUAL mothers), ii) sham-operated (sham mothers), and iii) unoperated (foster mothers). On day 18 of gestation (day 0, day in which a vaginal plug was detected), BUAL and sham mothers were anesthetized with $5 \%$ isofluorane delivered with oxygen, and underwent surgery under aseptic conditions. BUAL mothers had both uterine arteries ligated, whereas sham mothers underwent laparotomy and gentle handling of the uterine horns, according to a method previously described. ${ }^{30}$ After recovery from surgery, the rats were injected with $60 \mu \mathrm{L}$ of $100 \mathrm{mg} / 2$ $\mathrm{mL}$ tramadol hydrochloride (Tramal 100; CSL Limited, Parkville, Australia) intraperitoneally for analgesia and were returned to their normal housing conditions in individual cages. All pregnant rats were allowed to give birth spontaneously, and on day 1 (day 0 was day of birth) the pups were weighed. Then, after reducing the litter sizes by removing the pups with the highest and lowest birth weights, groups of eight pups (four males and four females) were fostered to unoperated foster mothers.

At weaning, 5-week-old male IUGR (offspring of BUAL mothers) and sham pups were assigned randomly to standard chow (6\% fat) or HF (43\% fat; Specialty Feed Services, Glen Forrest, Western Australia, Australia) diets such that all further experiments were of four separate rat groups: sham chow, sham HF, IUGR chow, and IUGR HF. This project was approved by the Australian National University Animal Experimentation Ethics Committee.

\section{Body Weight and Blood Parameters}

Rats were weighed every 2 weeks. Non-fasting tail-vein blood $(200 \mu \mathrm{L})$ was collected every two to four weeks (between 9:00 and 10:00 AM), and $200 \mu \mathrm{L}$ of fasting blood was collected at 13 and 23 weeks of age (between 9:00 and 10:00 AM) before glucose tolerance testing from conscious rats for determination of blood glucose, plasma insulin and serum triglyceride, and nonesterified fatty acid levels. Glucose levels were measured using a Glucometer (ACCUCHEK Advantage II; Roche, Mannheim, Germany). Plasma insulin levels were determined by radioimmunoassay (Linco Research, St. Louis, MO), and serum triglyceride and nonesterified fatty acid levels were measured by colorimetric enzyme kit assays (Wako Pure Chemical Industries Ltd., Osaka, Japan). Serum levels of iron were measured from 20- to 22-week-old rats using automated techniques (Clinical Chemistry; ACT Pathology, Canberra, Australia).

\section{Glucose Tolerance Testing}

At 13 and 23 weeks of age and after overnight fasting (16 to 18 hours), rats were subjected to an intraperitoneal glucose tolerance test using a $2 \mathrm{~g} / \mathrm{kg}$ of body weight bolus of $50 \%$ warmed glucose solution $(25 \mathrm{~g}$ in $50 \mathrm{~mL}$; Baxter Viaflex, New South Wales, Australia). Tail blood samples were taken before, as described earlier, and after glucose injection at 2.5, 10, 30, 60, and 120 minutes (all $100 \mu \mathrm{L}$ ) for glucose and plasma insulin determinations, using the analytical methods described earlier. 


\section{Tissue Harvesting and Histologic Assessment}

After 20 weeks of diet intervention (25 weeks of age), rats were sacrificed by $\mathrm{CO}_{2}$ inhalation. Pancreas and liver rapidly were dissected, weighed, and fixed immediately in $4 \%$ paraformaldehyde-phosphate buffered saline (PBS) solution for further histologic evaluation. After fixation, both pancreas and liver were embedded in paraffin. Series of $4-\mu \mathrm{m}-$ thick sections were cut and mounted on glass slides. Morphologic analysis of both tissues was performed in sections stained with $\mathrm{H} \& \mathrm{E}$. Fibrosis in pancreas sections was assessed by Masson trichrome staining, whereas the presence of iron deposits in the pancreas and liver was assessed by Perls staining. All histologic assessments, including scoring of abnormal characteristics using predetermined rating scales, were performed by two blinded observers (J.E.D. and C.J.N.).

\section{Immunohistochemistry}

Pancreatic sections for insulin immunohistochemistry (IHC) used for islet $\beta$-cell mass assessment were incubated with a $0.1 \%$ solution of hydrogen peroxidase methanol for $30 \mathrm{mi}-$ nutes to quench endogenous peroxidase activity. Sections then were rinsed with PBS and incubated for 30 minutes with guinea pig anti-insulin (1/100 A0564; Dako, Carpenteria, CA) diluted in $50 \mathrm{mmol} / \mathrm{L}$ Tris- $\mathrm{HCl}+1 \%$ bovine serum albumin buffer. After washes with PBS, sections were incubated with a horseradish peroxidase-labeled polymer conjugated to goat anti-rabbit immunoglobulin (EnVision + System horseradish peroxidase; Dako) for 30 minutes. Sections were washed again with PBS and developed using 3,3'-diaminobenzidine chromogen solution. The sections were counterstained with hematoxylin to visualize nuclei and mounted.

Further IHC assessments were performed on the Leica Bond automated system (Leica Microsystems Pty Ltd., North Ryde, New South Wales, Australia) using a standard protocol. Briefly, dewaxed sections of paraffin-embedded tissues were rehydrated through graded ethanol. Antigen sites were unmasked by heat treatment for 20 to 30 minutes in citrate buffer, pH 6.0 (Bond Epitope Retrieval Solution 1; Leica Microsystems), except for CD3 and CD20, in which EDTAbased buffer, pH 9.0 (Bond Epitope Retrieval Solution 2) was used. The following primary antibodies were used: guinea pig anti-insulin (1/100 dilution A0564; Dako), rabbit antiglucagon (1/200 dilution ab18461; Abcam, Cambridge, UK), rabbit anti-PDX-1 (1/500 dilution ab47267; Abcam), rabbit anti-Ki-67 (1/500 dilution ab15580; Abcam), rabbit anti-activated caspase 3 (1/100 dilution ab2302; Abcam), mouse anti-CD68/ED1 (1/2000 dilution MCA341GA; AbD Serotec, Oxford, UK), rabbit anti-CD3 (1/250 dilution A0452; DakoCytomation, Glostrup, Denmark), and rabbit anti-CD20 (1/250 dilution 250586; Abbiotec, San Diego, CA).

IHC single-staining protocols were performed using a poly-horseradish peroxidase secondary antibody and immunoreactivity was shown with 3,3'-diaminobenzidine chromogen solution (Leica Bond Polymer Refine Detection Kit;
Leica Microsystems), except for PDX-1 and CD68, which used a labeled streptavidin biotin alkaline phosphatase detection system with a red chromogen (Leica Bond Polymer Refine Detection Kit). Sequential double IHC staining was performed to examine the co-location of insulin and Ki-67 or activated caspase 3 . Insulin antibody was applied for $20 \mathrm{mi}-$ nutes using Bond Epitope Retrieval Solution 1 to the tissue section followed by the labeled streptavidin biotin alkaline phosphatase detection system with a red chromogen. Ki-67 antibody or activated caspase 3 antibody was then applied for 20 minutes using Bond Epitope Retrieval Solution 1 and the labeled streptavidin biotin horseradish peroxidase detection system with 3,3'-diaminobenzidine chromogen was used. All sections were counterstained with hematoxylin, coverslipped, viewed, and analyzed.

\section{Measurement of Islet $\beta$-Cell Mass}

Three serial sections of the pancreas (200 $\mu \mathrm{m}$ apart) manually immunostained for insulin were visualized using an Olympus IX71 inverted microscope and digital images were captured with a DP71 camera coupled to a U-RFL-T mercury burner (Olympus, Tokyo, Japan). For each section,
A

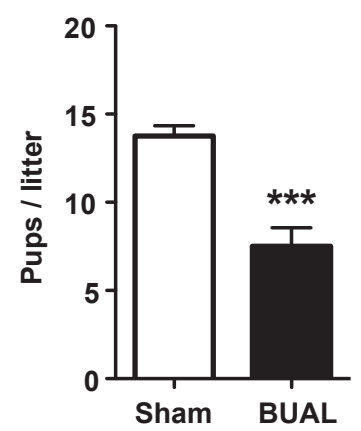

B

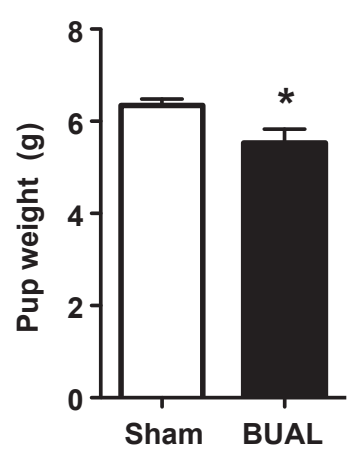

C

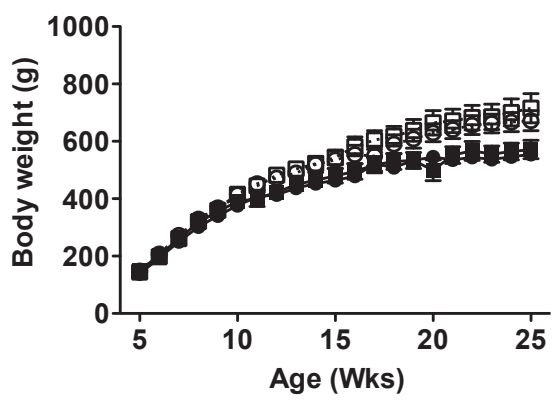

Figure 1 Effects of IUGR and diet on offspring body weight. A: Litter size at birth of sham and BUAL dams that underwent surgery. B: Average pup weight at day 1 in litters of sham and BUAL dams that underwent surgery. Values are means \pm SEM of 8 to 10 dams per group. ${ }^{*} P<0.05$, $* * * P<0.0005$. C: Body weight of sham-chow (black squares and black lines), IUGR-chow (black circles and black lines), sham-HF (white squares and dotted lines), and IUGR-HF (white circles and dotted lines) male rats from weaning. Values are means \pm SEM of 7 to 9 animals per group. C: Repeated-measures generalized linear model: effect of diet over time: $P<0.0001$. 
Table 1 Non-Fasting Blood Parameters of Male Sham-Chow, Sham-HF, IUGR-Chow, and IUGR-HF Rats at 7 and 20 Weeks of Age

\begin{tabular}{|c|c|c|c|c|c|}
\hline Non-fasting blood parameters & Sham-chow & Sham-HF & IUGR-chow & IUGR-HF & Two-way analysis of variance \\
\hline \multicolumn{6}{|l|}{ 7-week-old rats } \\
\hline Glucose level (mg/dL) & $111 \pm 4$ & $120 \pm 2$ & $109 \pm 2$ & $110 \pm 2^{\ddagger}$ & Surgery effect, $P<0.05$ \\
\hline Insulin level (ng/mL) & $0.6 \pm 0.1$ & $2.2 \pm 0.4^{\star}$ & $0.7 \pm 0.1$ & $2.1 \pm 0.6^{\dagger}$ & Diet effect, $P<0.01$ \\
\hline NEFA level (mmol/L) & $0.7 \pm 0.1$ & $1.1 \pm 0.1^{* *}$ & $0.6 \pm 0.1$ & $1.3 \pm 0.1^{\dagger \dagger \dagger}$ & Diet effect, $P<0.001$ \\
\hline TG level (mmol/L) & $6.3 \pm 0.7$ & $16.3 \pm 1.6^{* * *}$ & $5.7 \pm 0.6$ & $20.9 \pm 1.8^{\dagger \dagger \dagger}$ & Diet effect, $P<0.001$ \\
\hline \multicolumn{6}{|l|}{ 20-week-old rats } \\
\hline NEFA level (mmol/L) & $0.9 \pm 0.1$ & $1.1 \pm 0.1$ & $0.8 \pm 0.1$ & $1.1 \pm 0.1^{\dagger}$ & Diet effect, $P<0.01$ \\
\hline TG level (mmol/L) & $9.7 \pm 1.5$ & $17.8 \pm 1.4^{* *}$ & $9.3 \pm 1.2$ & $18.7 \pm 2.1^{\dagger \dagger \dagger}$ & Diet effect, $P<0.001$ \\
\hline
\end{tabular}

Data are means \pm SEM for seven to nine rats per group. All $P$ values were determined by two-way analysis of variance Bonferroni post hoc testing.

${ }^{*} P<0.05,{ }^{* *} P<0.01$, and ${ }^{* *} P<0.001$ versus sham-chow.

${ }^{\dagger} P<0.05,{ }^{\dagger \dagger \dagger} P<0.001$ versus IUGR-chow.

${ }^{\ddagger} P<0.05$ versus sham-HF.

NEFA, nonesterified fatty acids; TG, triglyceride.

the pancreatic (final magnification, $\times 40$ ) and the insulinpositive tissue areas (final magnification, $\times 160$ ), as well as islet size distribution, were determined using Image J software (version 1.43u; NIH, Bethesda, MD). Pancreatic $\beta$-cell mass was calculated as the product of the fractional $\beta$-cell area and the pancreas weight (in milligrams).

\section{Assessment of $\beta$-Cell Proliferation and Apoptosis}

Determination of proliferating and apoptotic $\beta$-cells was performed in insulin co-immunostained sections using antibodies for the proliferation marker Ki-67 and activated caspase 3, respectively. Representative digital images of pancreatic islets were taken (final magnification, $\times 400$ ). Approximately 1000 to $2000 \beta$-cell nuclei were counted per section by two independent assessors. The number of activated caspase 3 -positive cells was very low.

\section{Assessment of $\beta$-Cell Inflammation}

The presence of inflammatory cell infiltrates was evaluated in all pancreatic sections by IHC (final magnification, $\times 400$ ).
Antibodies against CD68/ED1, CD3, and CD20 were used as markers for macrophages, T lymphocyte, and B lymphocyte infiltration, respectively. The severity of inflammation was assessed using a semiquantitative scoring system of 0 to 3 , where 0 indicates none, 1 indicates mild, 2 indicates moderate, and 3 indicates severe according to the degree of cellular infiltration.

\section{Statistical Analysis}

Statistical analyses were performed using SPSS 20.0 software (IBM Corp., Armonk, NY). Data are presented as means \pm SEM. Each data point was derived from an individual rat. Comparisons between two groups were performed using the Student's $t$-test. The effects of diet (chow or HF), surgical group (sham or IUGR), and their interactions were performed by two-way analysis of variance followed by Bonferroni post hoc testing, or a repeated-measures generalized linear model if assessed over time. Chi-square testing was used to determine group differences in histologic scores. $P<0.05$ was considered statistically significant.

Table 2 Fasting Blood Parameters of Male Sham-Chow, Sham-HF, IUGR-Chow, and IUGR-HF Rats at 13 and 23 Weeks of Age

\begin{tabular}{|c|c|c|c|c|c|}
\hline Fasting blood parameters & Sham-chow & Sham-HF & IUGR-chow & IUGR-HF & Two-way analysis of variance \\
\hline \multicolumn{6}{|l|}{ 7-week-old rats } \\
\hline Glucose level (mg/dL) & $81 \pm 5$ & $102 \pm 3 * * *$ & $80 \pm 2$ & $95 \pm 2^{\dagger \dagger}$ & Diet effect, $P<0.001$ \\
\hline Insulin level $(\mathrm{ng} / \mathrm{mL})$ & $0.4 \pm 0.1$ & $1.9 \pm 0.5^{* *}$ & $0.5 \pm 0.1$ & $1.7 \pm 0.4^{\dagger}$ & Diet effect, $P<0.001$ \\
\hline NEFA level (mmol/L) & $1.3 \pm 0.1$ & $1.0 \pm 0.1$ & $1.5 \pm 0.1$ & $1.1 \pm 0.1$ & Diet effect, $P<0.01$ \\
\hline TG level (mmol/L) & $5.4 \pm 0.6$ & $7.43 \pm 1.1$ & $5.5 \pm 0.6$ & $9.0 \pm 1.4$ & Diet effect, $P<0.05$ \\
\hline \multicolumn{6}{|l|}{ 20-week-old rats } \\
\hline NEFA level (mmol/L) & $1.1 \pm 0.1$ & $1.1 \pm 0.1$ & $1.3 \pm 0.1$ & $1.2 \pm 0.1$ & - \\
\hline TG level (mmol/L) & $5.6 \pm 0.8$ & $8.0 \pm 1.2$ & $5.6 \pm 1.1$ & $9.8 \pm 1.1$ & Diet effect $P<0.05$ \\
\hline
\end{tabular}

Data are means \pm SEM for seven to nine rats per group. All $P$ values were determined by two-way analysis of variance Bonferroni post hoc testing.

${ }^{* *} P<0.01,{ }^{* * *} P<0.001$ versus sham-chow.

${ }^{\dagger} P<0.05,{ }^{\dagger \dagger} P<0.01$ versus IUGR-chow.

-, not significant; NEFA, nonesterified fatty acid; TG, triglyceride. 

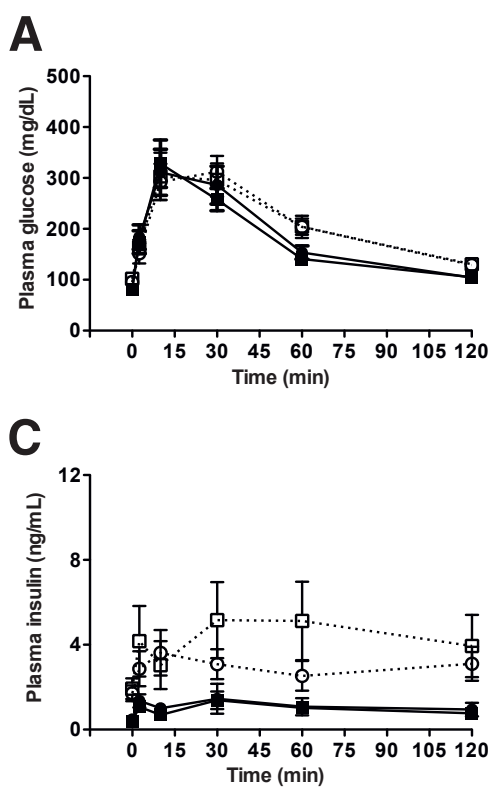

\section{Results}

\section{Body Weight}

Three separate cohorts comprising eight sham-operated dams and 10 BUAL dams were studied. Birth litter size of the BUAL compared with sham dams was reduced by $46 \%$ $(P<0.0005)$ (Figure 1A). The average pup weight measured at 1 day of age in BUAL litters was $13 \%$ lower than in sham litters $(P<0.05)$ (Figure 1B). Catch-up growth occurred quickly such that by weaning and allocation to chow and HF diet groups (5 weeks of age), the IUGR and sham male rat body weights did not differ (Figure 1C). Rat weight gain from weaning to 25 weeks of age in male
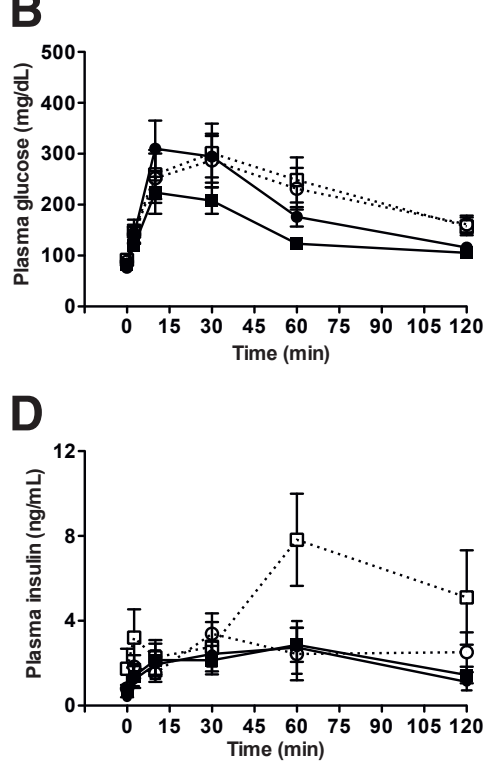

Figure 2 A HF diet, but not IUGR, causes mild impairment of glucose tolerance and an increase in insulin levels after glucose load. Blood glucose (A) and plasma insulin (C) responses in 13-week-old, and blood glucose (B) and plasma insulin (D) responses in 23-week-old sham-chow (black squares and black lines), IUGR-chow (black circles and black lines), sham-HF (white squares and dotted lines), and IUGR-HF (white circles and dotted lines) male rats during intraperitoneal glucose tolerance tests after an overnight fast. Values are means $\pm \operatorname{SEM}(n=7$ to 9 ). Repeatedmeasures generalized linear models: effect of diet over time, $P<0.05$ (A); effect of diet, $P<0.05$ (C).
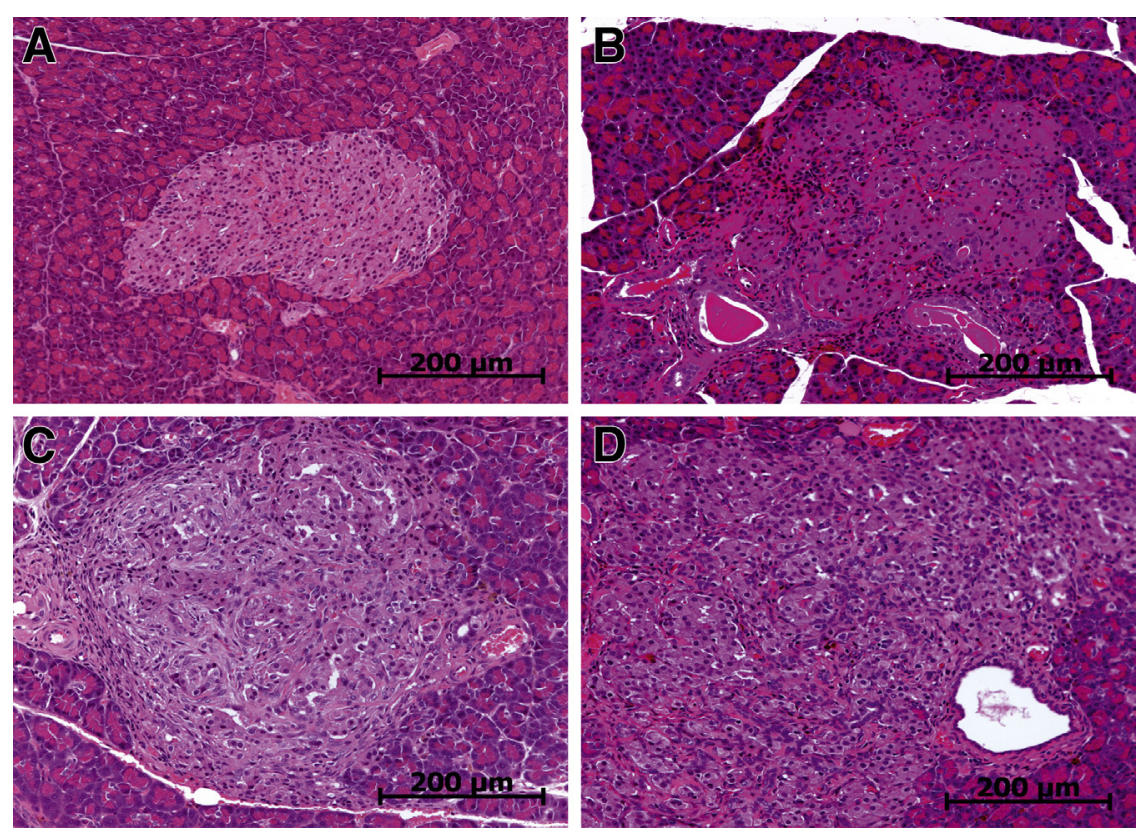

IUGR-chow and IUGR-HF rats did not differ from their respective sham-operated chow- and HF-fed controls (Figure 1C). By 25 weeks of age, however, the sham-HF and IUGR-HF rats weighed $40 \%$ and $21 \%$ more than the sham-chow and IUGR-chow rats, respectively (Figure 1C).

HF-Fed Rats Develop Hyperinsulinemia, Dyslipidemia, and Mild Increases in Blood Glucose Levels

Nonfasting blood parameters at 7 and 20 weeks of age are shown in Table 1. Fasting blood parameters at 13 and 23 weeks of age are shown in Table 2. HF feeding increased nonfasting levels of plasma insulin, serum triglycerides, and
Figure 3 Representative photomicrographs of islets in pancreatic sections from 25-week-old male sham-chow (A), sham-HF (B), IUGR-chow (C), and IUGR-HF (D) rats stained with H\&E. Original magnification, $\times 200$. 

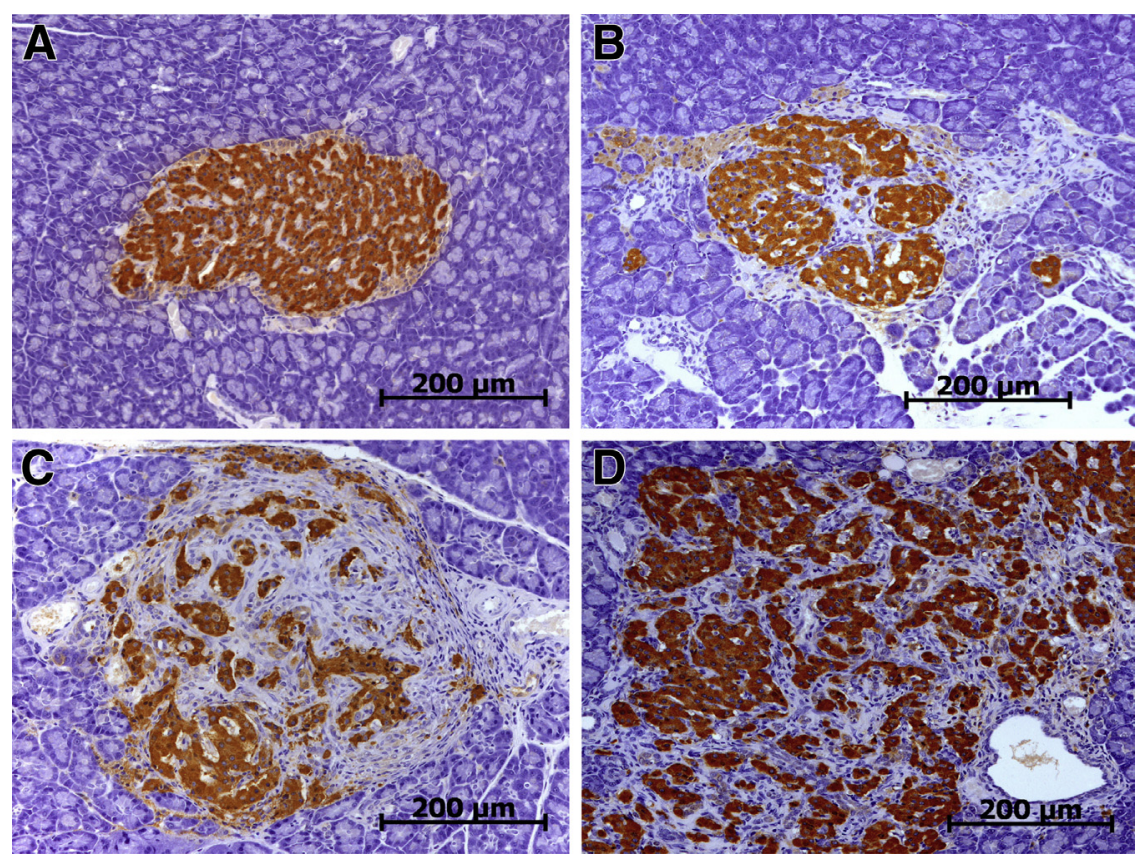

Figure 4 Representative photomicrographs of islets in pancreatic sections from 25-week-old male sham-chow (A), sham-HF (B), IUGR-chow (C), and IUGR-HF (D) rats immunostained for insulin (brown). Original magnification, $\times 200$. nonesterified fatty acids in both the sham and IUGR rat groups at 7 weeks of age, with a very similar pattern evident at 20 weeks of age (Table 1). HF feeding of both sham and IUGR rats also caused fasting hyperinsulinemia and a mild degree of fasting hypertriglyceridemia, however, in contrast to the fed-state, lower fasting nonesterified fatty acid levels (most evident at 13 weeks of age) (Table 2). HF feeding caused a mild increase in fasting and fed blood glucose levels in sham rats, but this effect occurred only in fasted IUGR rats (Tables 1 and 2). There was a tendency of IUGR to attenuate the effect of high-fat feeding on the non-fasting blood glucose (Table 1). At 20 to 22 weeks of age, serum levels of iron in sham and IUGR rats did not differ in those fed a chow diet $(57.6 \pm 8.2$ versus $47.7 \pm 3.2 \mu \mathrm{mol} / \mathrm{L})$ or $\mathrm{HF}$ diet $(51.6 \pm 3.8$ versus $47.5 \pm 2.3 \mu \mathrm{mol} / \mathrm{L})$.

\section{HF Feeding Causes Mild Impaired Glucose Tolerance and Hyperinsulinemia in Sham and IUGR Rats}

Glucose tolerance and insulin responses to glucose were assessed by intraperitoneal glucose tolerance tests at 13 and 23 weeks of age. Glucose tolerance was impaired mildly in sham-HF and IUGR-HF rats at 13 weeks of age, with a similar trend at 23 weeks of age (Figure 2, A and B). Insulin
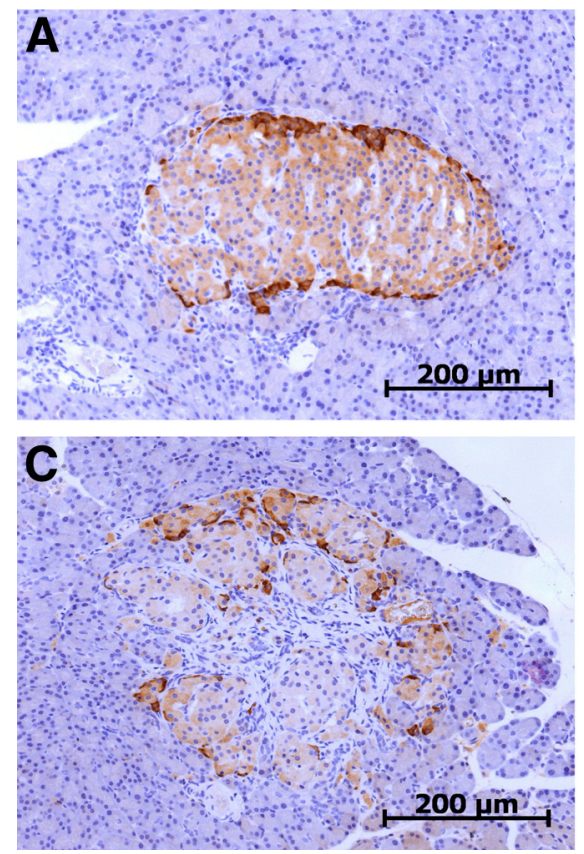
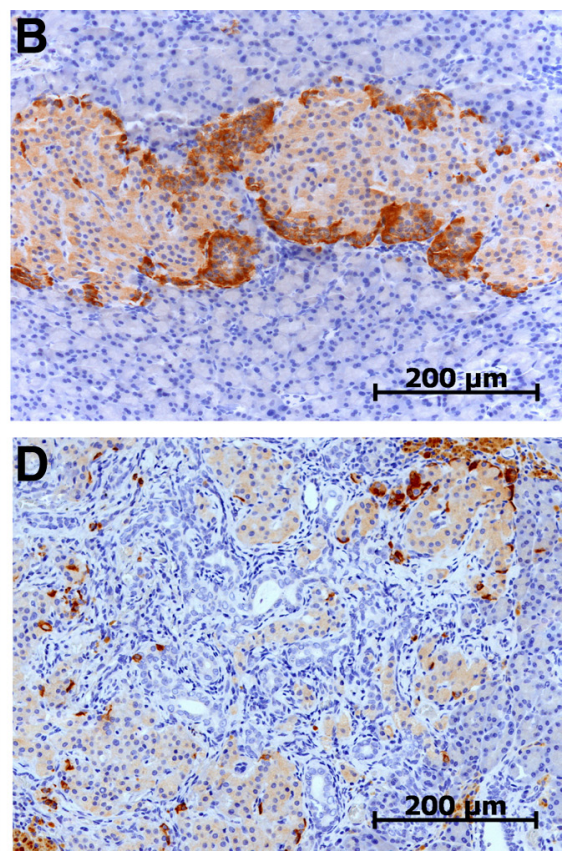

Figure 5 Representative photomicrographs of islets in pancreatic sections from 25-week-old male sham-chow (A), sham-HF (B), IUGR-chow (C), and IUGR-HF (D) rats immunostained for glucagon (brown). Original magnification, $\times 200$. 

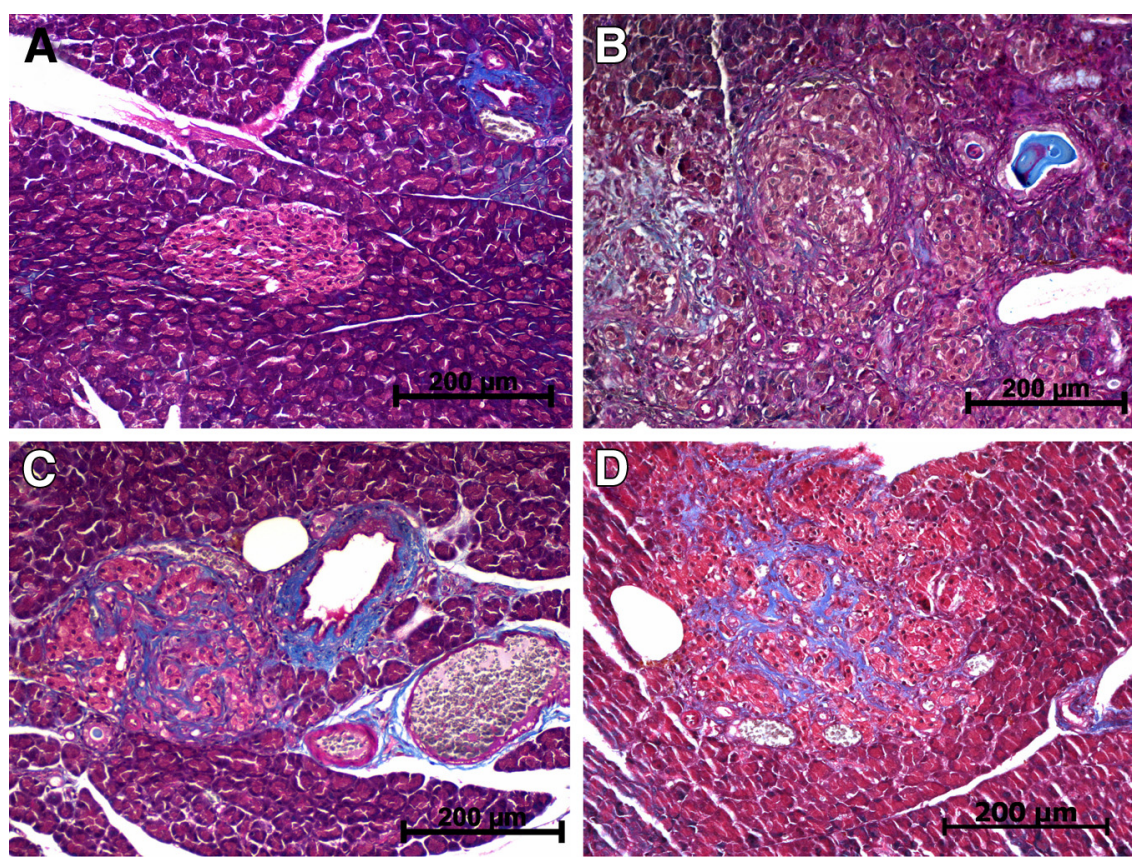

Figure 6 Representative photomicrographs of islets in pancreatic sections from 25-week-old male sham-chow (A), sham-HF (B), IUGR-chow (C), and IUGR-HF (D) rats stained with Masson trichrome for fibrosis (blue). Original magnification, $\times 200$. responses to the i.p. glucose load were increased in response to $\mathrm{HF}$ feeding in sham and IUGR rats at 13 weeks of age (Figure 2C). Interestingly, by 23 weeks of age, there was a trend for hyperinsulinemia after glucose load in sham-HF rats only (Figure 2D).

IUGR and HF Feeding Induces Abnormal Islet Morphology with Evidence of Fibrosis and Hemosiderosis

Islet morphology was assessed in pancreas sections from 25-week-old rats using H\&E, IHC for insulin and glucagon,
Masson trichrome, and Perl stains. Islets of sham-chow rats appeared normal in all pancreases examined (Figures 3A, $4 \mathrm{~A}, 5 \mathrm{~A}, 6 \mathrm{~A}$, and $7 \mathrm{~A}$ ), with the majority of cells immunostaining for insulin situated centrally (Figure 4A), and cells immunostaining for glucagon located at the islet perimeter (Figure 5A). There was no evidence of islet fibrosis (Figure 6A) or iron accumulation (Figure 7A) in the shamchow rat pancreases. Based on a blinded assessment of H\&E sections, pancreases of 5 of 8 sham-HF, 4 of 8 IUGRchow, and 8 of 9 IUGR-HF rats had at least several moderately to severely dysmorphic islets compared with none of 6 sham-chow pancreases (chi-square, $P=0.007$ ).
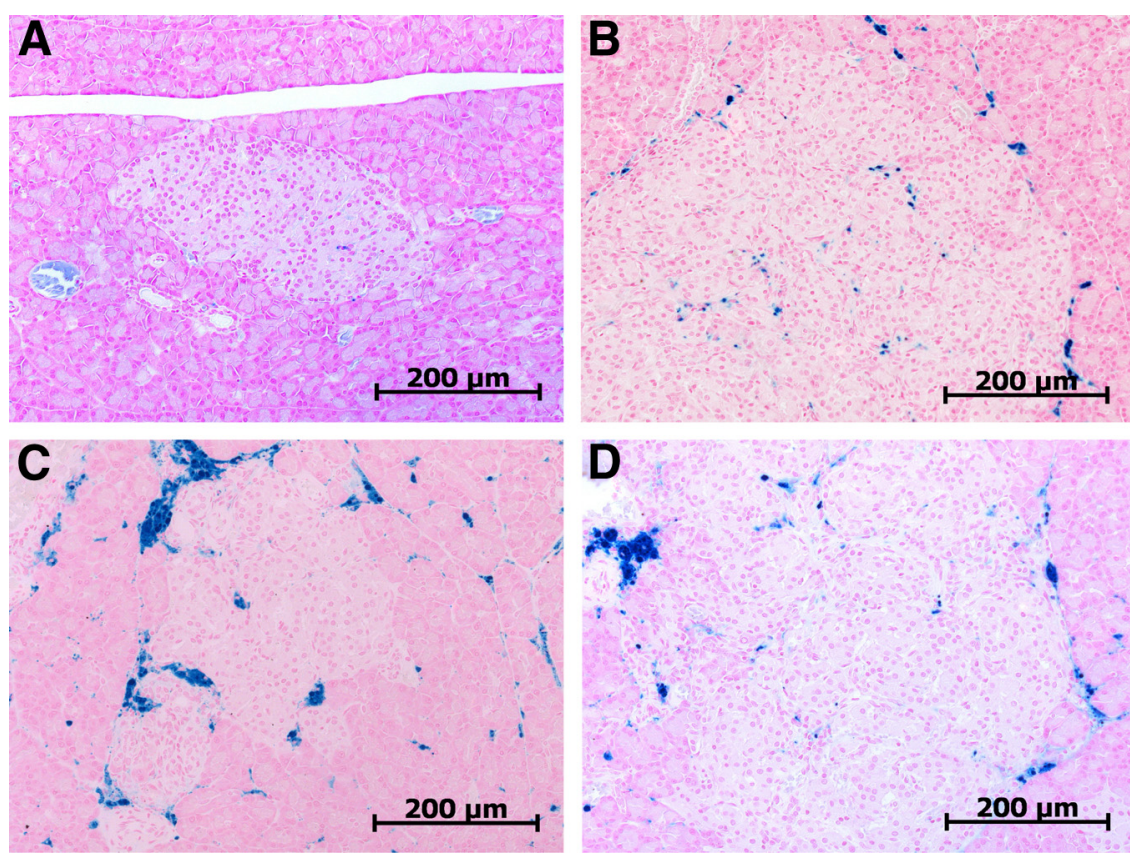

Figure 7 Representative photomicrographs of islets in pancreatic sections from 25-week-old male sham-chow (A), sham-HF (B), IUGR-chow (C), and IUGR-HF (D) rats stained with Perls for iron (blue). Original magnification, $\times 200$. 

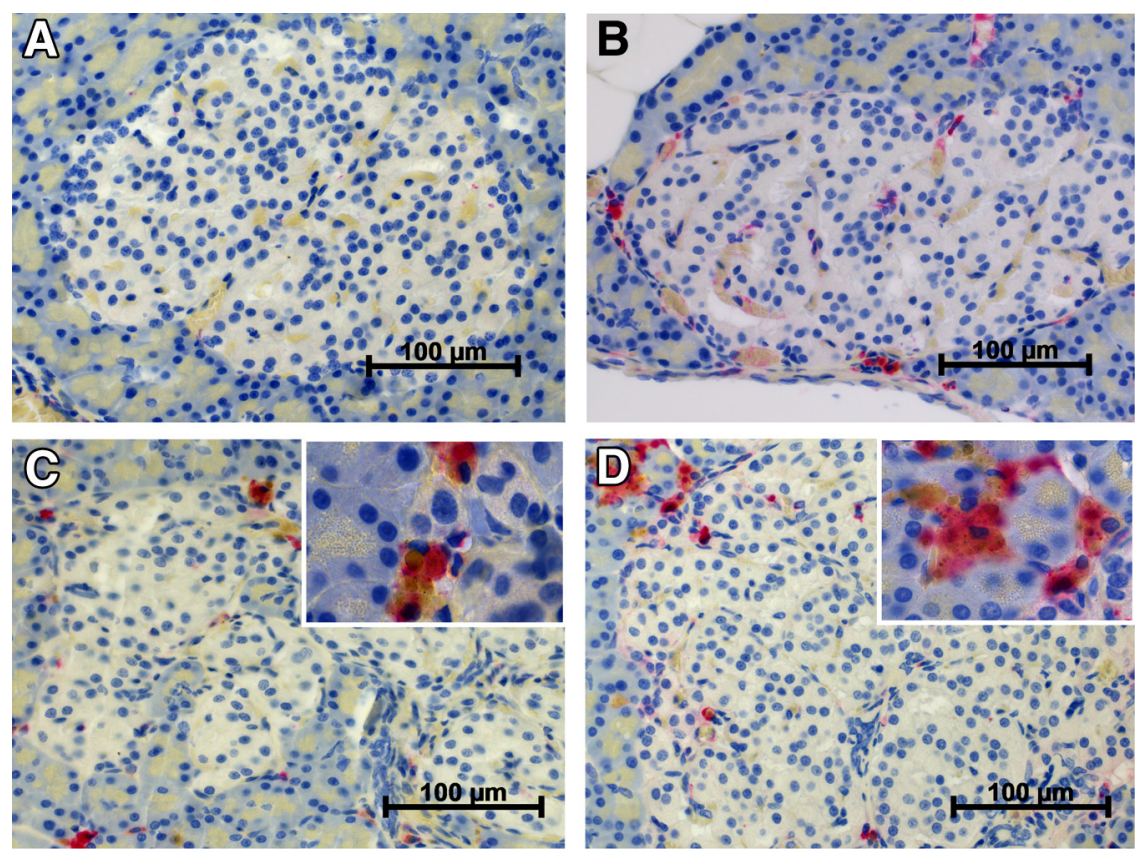

Figure 8 Representative photomicrographs of islets in pancreatic sections from 25-week-old male sham-chow (A), sham-HF (B), IUGR-chow (C), and IUGR-HF (D) rats immunostained for CD68 identifying macrophages (pink). Light brown staining (insets) is caused by iron accumulation in cells as shown by Perls staining in Figure 7. Original magnification: $\times 400(\mathbf{A}-\mathbf{D}) ; \times 1000$ (insets).
The percentage of moderately to severely dysmorphic islets per five low-power fields assessed was $0.5 \% \pm 0.4 \%$, $20 \% \pm 5 \%, 15 \% \pm 5 \%$, and $29 \% \pm 5 \%$ in the sham-chow, sham-HF, IUGR-chow, and IUGR-HF rat pancreases, respectively (two-way analysis of variance: diet effect, $P<0.005$; surgery effect, $P<0.05$ ). The dysmorphic islets
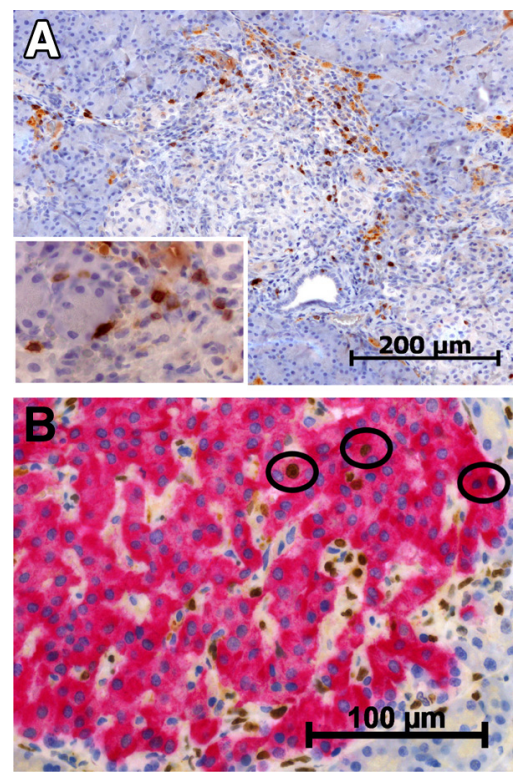

Figure 9 A: Representative photomicrographs of pancreatic sections from a 25-week-old male IUGR-HF rat immunostained for CD3 identifying T-lymphocytes (dark brown). Light brown staining is caused by iron accumulation in cells as is shown by Perls staining in Figure 7. B: A 25-week-old male sham-HF rat pancreas immunostained for the Ki-67 marker of cell proliferation (brown) and insulin (red). Examples of cells staining positive for Ki-67 are indicated by black circles. Original magnification: $\times 200($ A); $\times 630$ (inset); $\times 400$ (B). typically were increased in size and structurally disorganized (Figures 3, B-D; 4, B-D; 5, B-D; 6, B-D; and 7, $\mathrm{B}-\mathrm{C})$. The Masson trichrome stain of the more severely dysmorphic islets showed strands of fibrous tissue dividing the islets into nests of endocrine cells (Figure 6, B-D). In these abnormal islets, insulin IHC showed that the islet $\beta$ cells tended to be scattered throughout the nests of endocrine cells, with the intensity of insulin immunostaining in individual $\beta$-cells appearing normal (Figure 4, B-D). IHC for glucagon showed that the $\alpha$-cells in the dysmorphic islets tended to be at the periphery of the endocrine cell nests rather than at the islet perimeter only (Figure 5, B-D). Perls staining showed marked iron accumulation (hemosiderosis) associated with the abnormal-appearing islets in the majority of affected pancreases (Figure 7, $\mathrm{B}-\mathrm{D})$. The iron staining was predominantly in the peri-islet regions, but with some iron deposits also within the fibrous strands separating the nests of endocrine cells (Figure 7, $\mathrm{B}-\mathrm{D})$. Less frequent deposits of iron were seen within the exocrine pancreas tissue within macrophages. Perls staining of endocrine cells was not evident. Iron accumulation was undetectable in the liver sections of all groups studied (data not shown). Sham-HF and IUGR-HF rats had frequent fat vacuoles present within the exocrine tissue (data not shown).

\section{IUGR and HF Feeding Induces Peri-Islet Inflammation}

A subset of pancreases was immunostained to determine the presence of inflammatory cell infiltrates. At least moderate macrophage infiltration (CD68 IHC) was seen within abnormal islets in none of 4 sham-chow, 1 of 4 sham-HF, 1 of 4 IUGR-chow, and 3 of 5 IUGR-HF pancreas sections 


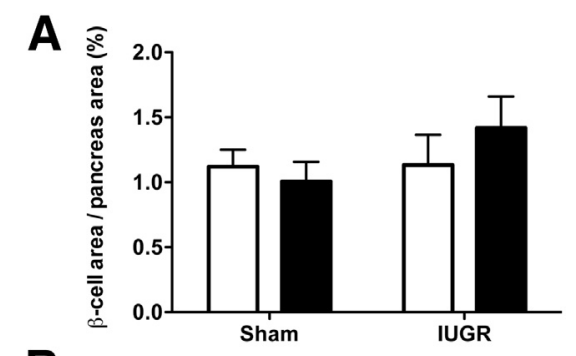

B
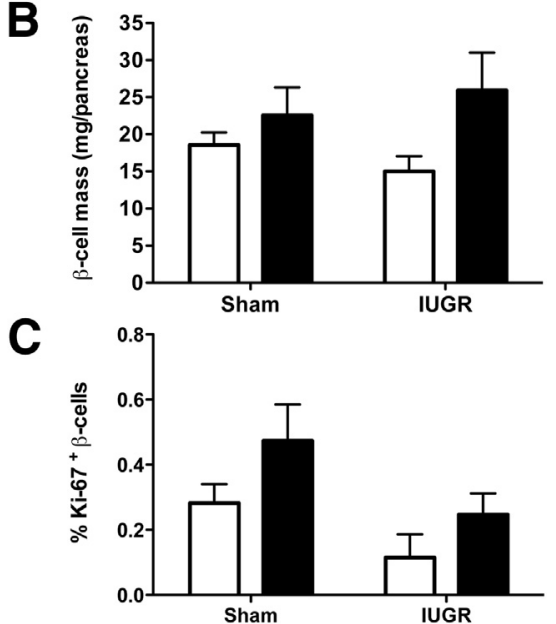

Figure 10 Pancreatic $\beta$-cell mass is preserved in islets of IUGR rats. Islet $\beta$-cell area/pancreas area (\%) (A) and islet $\beta$-cell mass ( $\mathrm{mg} /$ pancreas) (B) were measured in pancreas sections immunostained for insulin from 25week-old male sham-chow, sham-HF, IUGR-chow, and IUGR-HF rats. C: Percentage of Ki-67-positive $\beta$-cells in islets from the same rat groups. Results are means \pm SEM ( $n=4$ to 5$)$. Two-way analysis of variance: surgery effect, $P<0.05$ (C). White bars, chow; black bars, HF.

(Figure 8). At least moderate T lymphocyte (CD3) infiltration was also within some of the abnormal islets in none of sham-chow, 1 of 4 sham-HF, none of 4 IUGR-chow, and 2 of 5 IUGR-HF pancreases (Figure 9A). B-lymphocyte infiltration (CD20) was not evident in any of the groups (data not shown).

\section{$\beta$-Cell Mass and PDX-1 Immunostaining Is Preserved in} Islets of IUGR Rats

Islet $\beta$-cell area and mass was not altered in IUGR compared with sham rats, but there was a tendency for $\beta$-cell mass to be increased with HF feeding, particularly in the IUGR group (two-way analysis of variance diet effect, $P=0.07$ ) (Figure 10, A and B). Thus, despite severely dysmorphic islets in our IUGR model, islet $\beta$-cell mass was not compromised. Islet size distribution also was not altered, other than a tendency of the IUGR-HF rats to have an increased number of large islets (data not shown). Immunostaining for PDX-1 in islet endocrine cells was at least as strong in the cytoplasm of IUGR compared with sham rat pancreases (Figure 11). Furthermore, PDX-1 immunostaining of islet endocrine cell nuclei, although variable, was scored to be of moderate to strong intensity in the examined pancreases of none of 4 sham-chow, 2 of 4 sham-HF, 2 of 4 IUGR-chow, and 1 of 5 IUGR-HF rats (Figure 11). A representative photomicrograph of $\mathrm{Ki}-67-$ positive cells in a sham-HF rat is shown (Figure 9B). A significant reduction in the incorporation of $\mathrm{Ki}-67$ into $\beta$-cells of IUGR rats was observed (Figure 10C). Dual insulin/activated caspase 3 immunostaining also was performed, which showed extremely low numbers of apoptosing $\beta$-cells in all rat groups (data not shown).

\section{Discussion}

The key finding was that IUGR and HF diets after weaning independently can induce islet injury characterized by
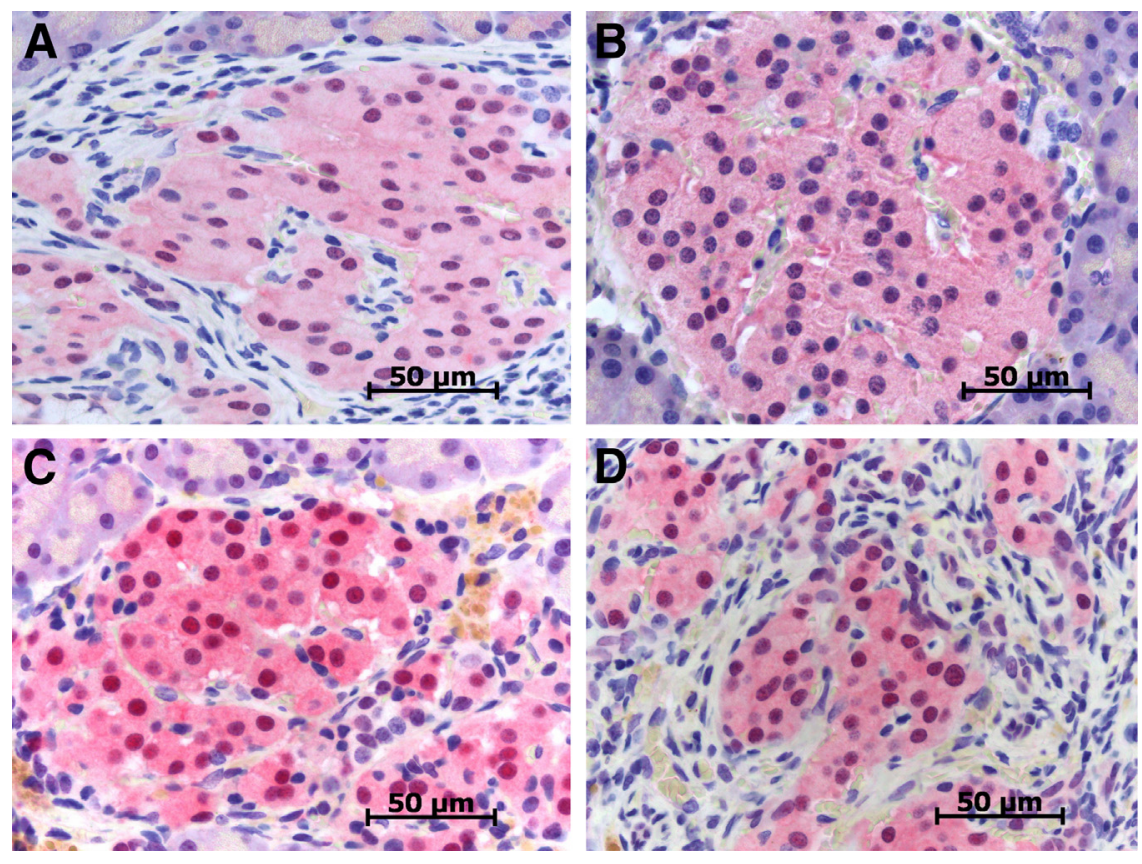

Figure 11 Representative photomicrographs of islets in pancreatic sections from 25-week-old male sham-chow (A), sham-HF (B), IUGR-chow (C), and IUGR-HF (D) rats immunostained for PDX-1 (pink). Original magnification, $\times 630$. 
inflammation, hemosiderosis, and fibrosis. Interestingly, similar islet injury previously was reported to occur in SD rats with aging, ${ }^{31-33}$ suggesting that IUGR and HF diet can both accelerate islet aging.

Islet inflammation and fibrosis have been reported in human type 2 diabetes, as well as in multiple rodent models of this condition. ${ }^{26,34}$ The role of islet inflammation in the pathogenesis of islet $\beta$-cell failure causing diabetes, therefore, is of intense interest. Inflammation likely is the cause of the fibrosis. ${ }^{26}$ HF feeding previously has been shown to cause the accumulation of macrophages in islets of C57BL/ $6 \mathrm{~J}$ mice and, more recently, in islets of nonhuman primates. ${ }^{34,35}$ The similar finding of islet-associated macrophage accumulation in the islets of sham-HF rats, therefore, is confirmatory. A similar effect of IUGR on the islets as occurred with HF feeding, however, is a new finding. In fact, the damaged islets of the sham-HF and IUGR-chow rats showed similar inflammatory and fibrosis features, suggesting possible convergence of pathogenic pathways. Although the presence of islet-associated macrophages often were seen in the IUGR and HF-fed rats, T-lymphocytes were seen less often, being evident in three of the examined pancreases (sham-HF and IUGR-HF). B-lymphocytes were not seen. T-lymphocytes have a critical role in the islet $\beta$-cell destruction in type 1 diabetes, ${ }^{26}$ and most likely are involved in setting the stage for the macrophagepredominant inflammation of adipose tissue in obesity. ${ }^{27}$ A pathogenic role for $\mathrm{T}$ cells in the inflammation and islet injury observed in this study and in type 2 diabetes therefore is likely.

The marked hemosiderosis observed surrounding and within the fibrous tissue of the abnormal islets of the IUGR and HF-fed rats is intriguing. The importance of the iron to the pathogenesis process is unknown, however, it could play a key role or simply be a bystander of the inflammation. Iron is well known to be toxic to islet $\beta$ cells, ${ }^{36-40}$ with evidence mounting that even mild forms of iron overload may contribute to the pathogenesis of type 2 diabetes. ${ }^{37,39}$ Epidemiological studies have shown increased rates of diabetes in those with the highest levels (quartiles or quintiles) of serum ferritin, ${ }^{4-43}$ and improvements in insulin sensitivity and glucose levels after phlebotomy in nonhemachromatosis individuals with or without diabetes. ${ }^{44,45}$ A protective effect of dietary iron restriction or iron chelation on loss of $\beta$-cell function and diabetes was observed in the obese leptindeficient $o b / o b$ mouse. ${ }^{36}$ Furthermore, it has been reported that the inflammatory cytokine IL- $1 \beta$ can induce divalent metal transporter 1 expression in $\beta$-cells and this correlates with increased $\beta$-cell iron content and reactive oxygen species formation. ${ }^{46}$ Also of interest is the finding that increased PDX-1 expression has been shown to facilitate IL-1 $\beta$-induced reactive oxygen species formation. ${ }^{46}$ It is certainly possible that islet inflammation in the IUGR and HF-fed rat islets up-regulates $\beta$-cell iron uptake and this promotes $\beta$-cell death via oxidative stress followed by accumulation of the iron from phagocytosed dead cells in the macrophages. Also worth noting is that IUGR infants have been reported to have altered iron homeostasis. ${ }^{47}$

All abnormal rat pancreases had a mixture of abnormaland normal-appearing islets. This could be owing to the development of newer healthy islets replacing old damaged islets in these pancreases, or it could be owing to patchy involvement of islets such that many are left unaffected. The latter could be explained if a threshold of inflammation is attained in some islets and the inflammation in those islets becomes self-perpetuating. If this is correct, antiinflammatory intervention at an early stage potentially could prevent the development of these abnormal islets by preventing the threshold being reached. Interestingly, the glucagon-like peptide 1 liraglutide has been reported to have anti-inflammatory effects in neurodegenerative diseases of the brain. ${ }^{48}$ It is always possible that the beneficial effects of exendin- 4 on the IUGR islet phenotype observed previously $^{24,25}$ were caused by anti-inflammatory properties. The patchy nature of the islet abnormalities is also a likely explanation as to how $\beta$-cell mass was preserved in the IUGR rats. The reason why Ki-67-positive $\beta$-cells were reduced but $\beta$-cell mass was unaffected in the IUGR rat islets is unknown.

A greater propensity to islet $\beta$-cell failure and diabetes in SD rats exposed to the combined insults of IUGR and HF diet in this study was not found. In addition, the metabolic and islet phenotype of the IUGR rats of the current study were very different from those reported by the Simmons group. ${ }^{17,22-25}$ In the current studies, islet expression of PDX-1, islet $\beta$-cell mass, and glucose tolerance were maintained. The marked reduction in PDX-1 expression in previous studies $^{22,23}$ is likely to contribute to the markedly reduced $\beta$-cell mass observed. The reason for the difference between the two models is unknown but it could relate to different severities of IUGR between studies. Birth weight in IUGR pups of the current study were reduced by $13 \%$, compared with $15 \%$ in the initial study by Simmons et al. ${ }^{17}$ Other possibilities could be subtle differences in the way the surgery was performed, the anesthetic used, the content of diets including iron content, housing conditions, or it could be owing to genetic differences in susceptibility to islet damage between the two different substrains of SD rats.

Finally, the current study results suggest that both IUGR and HF diet after weaning accelerate aging of rat pancreatic islets. Understanding the mechanisms is key to the development of targeted therapies to prevent this aging. In particular, the role of iron in the pathogenic process that is induced in islets by IUGR and HF diet needs further investigation. If high iron stores are found to have a pathogenic or even a permissive role in this process, then these findings will have important implications for the clinical monitoring and managing of body iron stores. 


\section{Acknowledgments}

We thank Elaine G. Bean, Lorraine Johnson, and Angeline Josiah for their expert technical assistance.

\section{References}

1. Prentki M, Nolan CJ: Islet beta cell failure in type 2 diabetes. J Clin Invest 2006, 116:1802-1812

2. Nolan CJ, Damm P, Prentki M: Type 2 diabetes across generations: from pathophysiology to prevention and management. Lancet 2011, 378:169-181

3. Defronzo RA: Banting lecture. From the triumvirate to the ominous octet: a new paradigm for the treatment of type 2 diabetes mellitus. Diabetes 2009, 58:773-795

4. Shaw JE, Sicree RA, Zimmet PZ: Global estimates of the prevalence of diabetes for 2010 and 2030. Diabetes Res Clin Pract 2010, 87:4-14

5. Colagiuri S: Diabesity: therapeutic options. Diabetes Obes Metab 2010, 12:463-473

6. Poulsen P, Grunnet LG, Pilgaard K, Storgaard H, Alibegovic A, Sonne MP, Carstensen B, Beck-Nielsen H, Vaag A: Increased risk of type 2 diabetes in elderly twins. Diabetes 2009, 58:1350-1355

7. Barker DJ, Hales CN, Fall CH, Osmond C, Phipps K, Clark PM: Type 2 (non-insulin-dependent) diabetes mellitus, hypertension and hyperlipidaemia (syndrome $\mathrm{X}$ ): relation to reduced fetal growth. Diabetologia 1993, 36:62-67

8. Mi J, Law C, Zhang KL, Osmond C, Stein C, Barker D: Effects of infant birthweight and maternal body mass index in pregnancy on components of the insulin resistance syndrome in China. Ann Intern Med 2000, 132:253-260

9. Simmons R: Developmental origins of adult metabolic disease: concepts and controversies. Trends Endocrinol Metab 2005, 16:390-394

10. Kaijser M, Bonamy AK, Akre O, Cnattingius S, Granath F, Norman M, Ekbom A: Perinatal risk factors for diabetes in later life. Diabetes 2009, 58:523-526

11. Kingdom J, Huppertz B, Seaward G, Kaufmann P: Development of the placental villous tree and its consequences for fetal growth. Eur J Obstet Gynecol Reprod Biol 2000, 92:35-43

12. Baschat AA: Fetal responses to placental insufficiency: an update. BJOG 2004, 111:1031-1041

13. Dahri S, Reusens B, Remacle C, Hoet JJ: Nutritional influences on pancreatic development and potential links with non-insulin-dependent diabetes. Proc Nutr Soc 1995, 54:345-356

14. Wilson MR, Hughes SJ: The effect of maternal protein deficiency during pregnancy and lactation on glucose tolerance and pancreatic islet function in adult rat offspring. J Endocrinol 1997, 154: 177-185

15. Petrik J, Reusens B, Arany E, Remacle C, Coelho C, Hoet JJ, Hill DJ: A low protein diet alters the balance of islet cell replication and apoptosis in the fetal and neonatal rat and is associated with a reduced pancreatic expression of insulin-like growth factor-II. Endocrinology 1999, 140:4861-4873

16. Cottrell EC, Seckl JR: Prenatal stress, glucocorticoids and the programming of adult disease. Front Behav Neurosci 2009, 3:19

17. Simmons RA, Templeton LJ, Gertz SJ: Intrauterine growth retardation leads to the development of type 2 diabetes in the rat. Diabetes 2001, 50:2279-2286

18. Valtat B, Dupuis C, Zenaty D, Singh-Estivalet A, Tronche F, Breant B, Blondeau B: Genetic evidence of the programming of beta cell mass and function by glucocorticoids in mice. Diabetologia 2011, 54: 350-359

19. Jansson T, Lambert GW: Effect of intrauterine growth restriction on blood pressure, glucose tolerance and sympathetic nervous system activity in the rat at 3-4 months of age. J Hypertens 1999, 17: $1239-1248$
20. Laker RC, Gallo LA, Wlodek ME, Siebel AL, Wadley GD, McConell GK: Short-term exercise training early in life restores deficits in pancreatic beta-cell mass associated with growth restriction in adult male rats. Am J Physiol Endocrinol Metab 2011, 301: E931-E940

21. Garofano A, Czernichow P, Breant B: In utero undernutrition impairs rat beta-cell development. Diabetologia 1997, 40:1231-1234

22. Park JH, Stoffers DA, Nicholls RD, Simmons RA: Development of type 2 diabetes following intrauterine growth retardation in rats is associated with progressive epigenetic silencing of Pdx1. J Clin Invest 2008, 118:2316-2324

23. Thompson RF, Fazzari MJ, Niu H, Barzilai N, Simmons RA, Greally JM: Experimental intrauterine growth restriction induces alterations in DNA methylation and gene expression in pancreatic islets of rats. J Biol Chem 2010, 285:15111-15118

24. Stoffers DA, Desai BM, DeLeon DD, Simmons RA: Neonatal exendin-4 prevents the development of diabetes in the intrauterine growth retarded rat. Diabetes 2003, 52:734-740

25. Ham JN, Crutchlow MF, Desai BM, Simmons RA, Stoffers DA: Exendin-4 normalizes islet vascularity in intrauterine growth restricted rats: potential role of VEGF. Pediatr Res 2009, 66:42-46

26. Donath MY, Shoelson SE: Type 2 diabetes as an inflammatory disease. Nat Rev Immunol 2011, 11:98-107

27. Nikolajczyk BS, Jagannathan-Bogdan M, Denis GV: The outliers become a stampede as immunometabolism reaches a tipping point. Immunol Rev 2012, 249:253-275

28. Amarilyo G, Oren A, Mimouni FB, Ochshorn Y, Deutsch V, Mandel D: Increased cord serum inflammatory markers in small-forgestational-age neonates. J Perinatol 2011, 31:30-32

29. Roman A, Desai N, Rochelson B, Gupta M, Solanki M, Xue X, Chatterjee PK, Metz CN: Maternal magnesium supplementation reduces intrauterine growth restriction and suppresses inflammation in a rat model. Am J Obstet Gynecol 2013, 208:383.e1-383.e7

30. Ogata ES, Bussey ME, LaBarbera A, Finley S: Altered growth, hypoglycemia, hypoalaninemia, and ketonemia in the young rat: postnatal consequences of intrauterine growth retardation. Pediatr Res 1985, 19:32-37

31. Dillberger JE: Age-related pancreatic islet changes in Sprague-Dawley rats. Toxicol Pathol 1994, 22:48-55

32. Molon-Noblot S, Keenan KP, Coleman JB, Hoe CM, Laroque P: The effects of ad libitum overfeeding and moderate and marked dietary restriction on age-related spontaneous pancreatic islet pathology in Sprague-Dawley rats. Toxicol Pathol 2001, 29:353-362

33. Reaven EP, Reaven GM: Structure and function changes in the endocrine pancreas of aging rats with reference to the modulating effects of exercise and caloric restriction. J Clin Invest 1981, 68:75-84

34. Ehses JA, Perren A, Eppler E, Ribaux P, Pospisilik JA, Maor-Cahn R, Gueripel X, Ellingsgaard H, Schneider MK, Biollaz G, Fontana A, Reinecke M, Homo-Delarche F, Donath MY: Increased number of islet-associated macrophages in type 2 diabetes. Diabetes 2007, 56: 2356-2370

35. Nicol LE, Grant WR, Comstock SM, Nguyen ML, Smith MS, Grove KL, Marks DL: Pancreatic inflammation and increased islet macrophages in insulin-resistant juvenile primates. J Endocrinol 2013, 217:207-213

36. Cooksey RC, Jones D, Gabrielsen S, Huang J, Simcox JA, Luo B, Soesanto Y, Rienhoff H, Abel ED, McClain DA: Dietary iron restriction or iron chelation protects from diabetes and loss of beta-cell function in the obese (ob/ob lep-/-) mouse. Am J Physiol Endocrinol Metab 2010, 298:E1236-E1243

37. Rajpathak SN, Crandall JP, Wylie-Rosett J, Kabat GC, Rohan TE, $\mathrm{Hu}$ FB: The role of iron in type 2 diabetes in humans. Biochim Biophys Acta 2009, 1790:671-681

38. Cheng K, Ho K, Stokes R, Scott C, Lau SM, Hawthorne WJ, O'Connell PJ, Loudovaris T, Kay TW, Kulkarni RN, Okada T, Wang XL, Yim SH, Shah Y, Grey ST, Biankin AV, Kench JG, Laybutt DR, Gonzalez FJ, Kahn CR, Gunton JE: Hypoxia-inducible 
factor-1alpha regulates beta cell function in mouse and human islets. J Clin Invest 2010, 120:2171-2183

39. Simcox JA, McClain DA: Iron and diabetes risk. Cell Metab 2013, 17: 329-341

40. McClain DA, Abraham D, Rogers J, Brady R, Gault P, Ajioka R, Kushner JP: High prevalence of abnormal glucose homeostasis secondary to decreased insulin secretion in individuals with hereditary haemochromatosis. Diabetologia 2006, 49:1661-1669

41. Forouhi NG, Harding AH, Allison M, Sandhu MS, Welch A, Luben R, Bingham S, Khaw KT, Wareham NJ: Elevated serum ferritin levels predict new-onset type 2 diabetes: results from the EPIC-Norfolk prospective study. Diabetologia 2007, 50:949-956

42. Jiang R, Ma J, Ascherio A, Stampfer MJ, Willett WC, Hu FB: Dietary iron intake and blood donations in relation to risk of type 2 diabetes in men: a prospective cohort study. Am J Clin Nutr 2004, 79:70-75

43. Sun L, Zong G, Pan A, Ye X, Li H, Yu Z, Zhao Y, Zou S, Yu D, Jin Q, $\mathrm{Hu} F B$, Lin X: Elevated plasma ferritin is associated with increased incidence of type 2 diabetes in middle-aged and elderly Chinese adults. J Nutr 2013, 143:1459-1465
44. Facchini FS, Hua NW, Stoohs RA: Effect of iron depletion in carbohydrate-intolerant patients with clinical evidence of nonalcoholic fatty liver disease. Gastroenterology 2002, 122:931-939

45. Fernandez-Real JM, Penarroja G, Castro A, Garcia-Bragado F, LopezBermejo A, Ricart W: Blood letting in high-ferritin type 2 diabetes: effects on vascular reactivity. Diabetes Care 2002, 25:2249-2255

46. Hansen JB, Tonnesen MF, Madsen AN, Hagedorn PH, Friberg J, Grunnet LG, Heller RS, Nielsen AO, Storling J, Baeyens L, AnkerKitai L, Qvortrup K, Bouwens L, Efrat S, Aalund M, Andrews NC, Billestrup N, Karlsen AE, Holst B, Pociot F, Mandrup-Poulsen T: Divalent metal transporter 1 regulates iron-mediated ROS and pancreatic beta cell fate in response to cytokines. Cell Metab 2012, 16:449-461

47. Briana DD, Boutsikou T, Baka S, Boutsikou M, Stamati L, Hassiakos D, Gourgiotis D, Malamitsi-Puchner A: Perinatal role of hepcidin and iron homeostasis in full-term intrauterine growthrestricted infants. Eur J Haematol 2013, 90:37-44

48. Parthsarathy V, Holscher C: The type 2 diabetes drug liraglutide reduces chronic inflammation induced by irradiation in the mouse brain. Eur J Pharmacol 2013, 700:42-50 